\title{
Does cortisol manipulation influence outmigration behaviour, survival and growth of sea trout? A field test of carryover effects in wild fish
}

\author{
Jonathan D. Midwood ${ }^{1, *}$, Martin Hage Larsen ${ }^{2}$, Mikkel Boel $^{2}$, Niels Jepsen ${ }^{2}$, \\ Kim Aarestrup ${ }^{2}$, Steven J. Cooke ${ }^{1}$ \\ ${ }^{1}$ Fish Ecology and Conservation Physiology Laboratory, Department of Biology and Institute of Environmental Science, \\ Carleton University, 1125 Colonel By Drive, Ottawa, Ontario K1S 5B6, Canada \\ ${ }^{2}$ National Institute of Aquatic Resources, Freshwater Fisheries, Technical University of Denmark, Vejlsøvej 39, \\ 8600 Silkeborg, Denmark
}

\begin{abstract}
For anadromous brown trout Salmo trutta, the transition from life in freshwater to the marine environment is an inherently challenging and dangerous period characterized by high levels of mortality. As such, smoltification is a relevant life-history phase to examine how physiological state, in particular glucocorticoids, influences fitness-oriented endpoints such as migration timing and survival. We experimentally assessed the effect of cortisol by combining passive integrated transponder (PIT) telemetry with a physiologically relevant exogenous cortisol manipulation (i.e. intracoelomic injection) in juvenile sea trout in the Gudsø Stream, Denmark. Individual survival, migration behaviour (timing and speed), and growth were assessed for 4 treatment categories: control (CO), sham (SH), and low- (LW; $25 \mathrm{mg} \mathrm{kg}^{-1}$ ) and high-dose (HI; $100 \mathrm{mg} \mathrm{kg}^{-1}$ ) cortisol. There was no difference in the timing of migration among treatments, but trout in the HI treatment had lower survival rates to the lower station (41.6\%) when compared to the CO $(53.9 \%)$ and SH (52.3\%) groups. After migration, the system was electroshocked again to contrast growth of trout that remained in the system. HI, LW and SH individuals recaptured in the stream had lower growth rates for length than the CO treatments; HI and LW also had significantly lower growth rates for mass than $\mathrm{CO}$ trout. Future monitoring of this population may demonstrate the long-term repercussions of chronic stress as trout return from the ocean. This study provides contributions to our understanding of the relationship between organismal condition and fitness while elucidating the potential for carryover effects, i.e. lasting effects that influence future success.
\end{abstract}

KEY WORDS: Allostasis $\cdot$ Carryover effects $\cdot$ Migration $\cdot$ Stress

\section{INTRODUCTION}

Factors that influence the growth and survival of early life stages of fishes are critical for determining the long-term structure and viability of their population (Schlosser 1991). For anadromous brown trout Salmo trutta (hereafter called sea trout), the early phase of their life cycle occurs in freshwater tributaries that feed into the ocean. For this species and other salmonids, the pre-smolt and smolt life stages are an exceptionally important and sensitive period. Energy reserves are typically low, yet these fish are exposed to high levels of predation along their migratory route and must undergo a physiologically challenging transition from freshwater into a saline environment (Aarestrup et al. 2000, Jonsson \& Jonsson 2011). Lasting effects such as body condition or parasite load from their experience on their natal grounds (e.g. carryover effects) may dictate the timing and success of their migration to the ocean and ultimately 
their survival (Norris 2005, Harrison et al. 2011). Despite the potential for carryover effects, little work has been done to determine how environmental conditions in natal rivers may affect sea trout as they transition to the ocean (Jonsson \& Jonsson 2011).

Wild populations of fish are subject to a wide variety of both anthropogenic and natural challenges that can range from acute stressors such as predation attempts or fisheries interactions to chronic stressors like habitat alteration and pollution (Pickering 1989, Schlosser 1991, Fraser \& Gilliam 1992, Wang et al. 2000). In teleost fishes, elevated plasma cortisol is a natural response to stress, with circulating levels providing a useful physiological indicator of a fish's stress level (reviewed in Iwama 1998). The corticosteroid pathway helps mobilize energy reserves in response to a stressor, thereby increasing metabolic activity (reviewed in Mommsen et al. 1999). While these changes increase the amount of energy available in order for an individual to respond to an immediate stressor, they also reduce the amount of energy available for essential functions such as growth and reproduction (Redding et al. 1986, Carragher et al. 1989, Gregory \& Wood 1999, Fullerton et al. 2000). The stress response axis also plays an important role in allostasis or adaptation to novel environmental conditions such as those caused by an acute human disturbance. While short-term allostasis may allow fish to survive this type of environmental perturbation, the carryover effects of activation of the stress axis may also reduce long-term fitness (Schreck 2010, Harrison et al. 2011) as observed in studies of compensatory growth (Metcalfe \& Monaghan 2003).

Intra-coelomic injection of cortisol is a common method for artificially increasing plasma cortisol in teleost fishes, albeit mostly in a laboratory context (Pickering \& Duston 1983, Pickering 1993, Gamperl et al. 1994, Hoogenboom et al. 2011). Using this technique, early laboratory experiments were instrumental in elucidating the mechanisms behind an individual's response to stress (reviewed in Barton \& Iwama 1991, Pickering 1993); however, there is still a need to apply this understanding to wild populations to put such work into an ecological context. Similar to laboratory studies, exogenous cortisol manipulation in wild populations of fish enables an experimental approach with both treatment and control groups. This approach was used recently to document a carryover effect (decreased survival compared to a control) in largemouth bass Micropterus salmoides that were treated with cortisol and released into their natural environment when exposed to a temporally separated second stressor (i.e. winter hypoxia; O'Connor et al. 2010). An inte- gral component of this study was the combined use of a physiological manipulation (cortisol injection) and biotelemetry. Together, they enabled the researchers to monitor the individual movements and behaviour of both treated and control fish in a natural setting.

Biotelemetry offers one of the best options for monitoring a fish's response to an external perturbation in a natural setting (Cooke et al. 2004). This technology allows for the monitoring of individual movements and behaviour and, while radio or acoustic tracking can provide accurate movement information for individuals, they are cost prohibitive for applications that involve large numbers of fish. Passive integrated transponder (PIT) tags are a comparatively inexpensive and an easily applied option that also provide individual coding for each fish, have minimal effects on growth and survival, and have a very long life span (Zydlewski et al. 2001, Gries \& Letcher 2002). By combining these tags with cross-stream PIT scanning arrays, long-term continuous data on individual movements can be acquired (Zydlewski et al. 2001, Gibbons \& Andrews 2004).

Despite their potential ecological importance, there is a shortage of studies that document the response of wild fish to stress in their natural environment and its potential for carryover effects (Cooke \& O'Connor 2010, O'Connor et al. 2011, Nagrodski et al. 2013). For sea trout, little work has been done to understand relationships between ecology (e.g. population-level processes) and physiology (e.g. organismal condition and health) in a natural setting (Jonsson \& Jonsson 2011), especially during early life-stages. Our goals were therefore to combine PIT telemetry with a cortisol manipulation to experimentally assess the impact of a chronic stressor on the individual growth, survival, and migration behaviour of wild, free-swimming sea trout. In sea trout, chronic stressors are known to impair growth and since migration timing is linked to an individual's size, this stressor may also delay their migration. We therefore predict that stressed individuals will experience impaired growth, which will result in delayed migration relative to controls. We also predict that stressed individuals will not be as successful at undertaking the physiologically demanding migration, resulting in lower survival rates for the stressed treatments.

\section{MATERIALS AND METHODS}

\section{Study location and fish sampling}

Brown trout smolts exhibit partial migration, whereby a portion of the population migrates to lakes or the 


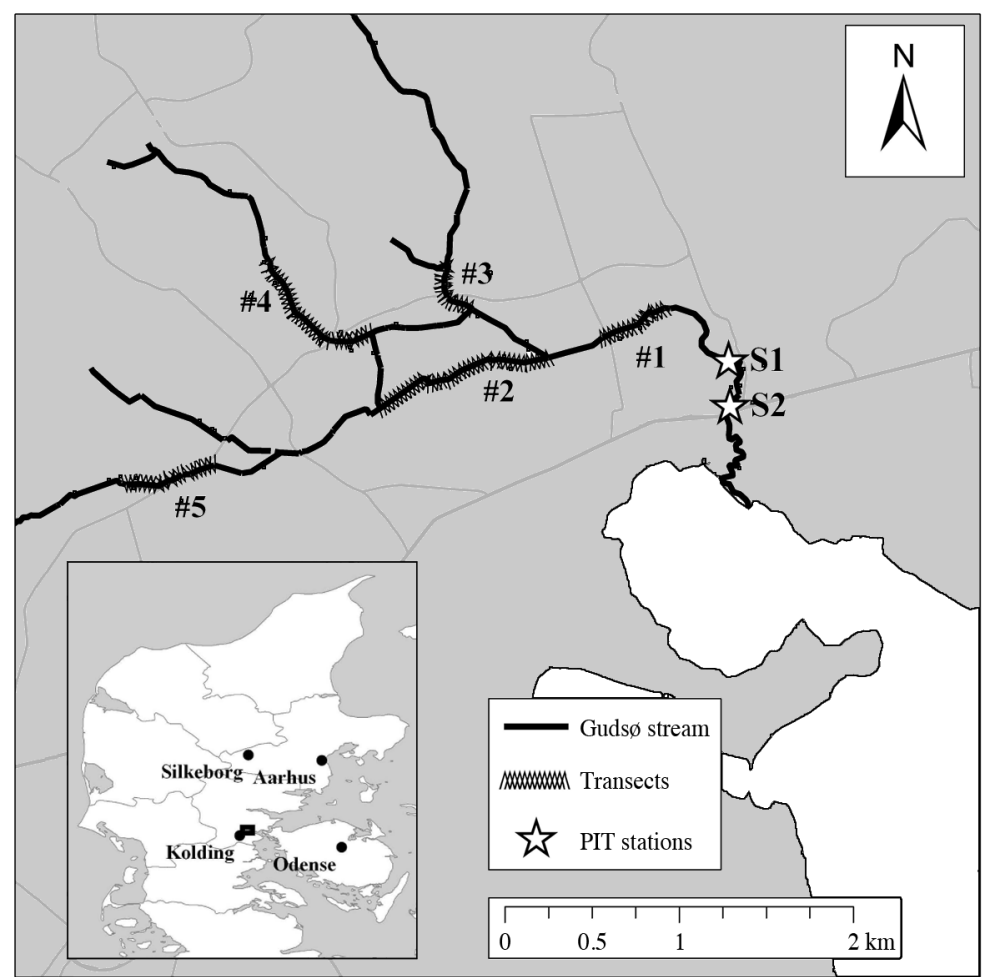

Fig. 1. Inset: location of Gudsø Stream (northeast of Kolding, Denmark; box). Main map: location within the stream of the 5 transects where trout were captured and the passive integrated transponder (PIT) stations (S1 and S2). A millpond is situated between S1 and S2 and serves as a potential population sink for migrating trout

ocean and the rest remain in their natal system and become residents (Jonsson \& Jonsson 1993, Økland et al. 1993, Boel 2012). Polymorphs can co-exist because migrating trout have higher mortality rates but resident trout have lower fecundity (Jonsson 1985, Elliott 1993). Their individual condition and local resources in the late fall are thought to be the prime drivers behind smoltification, such that trout with lower food requirements tend to become residents, and those with higher requirements migrate from the river (Forseth et al. 1999, Cucherousset et al. 2005). We therefore opted to physiologically manipulate the trout after they had made the 'decision' to migrate or stay, to ensure that the stressor would not determine their smolt status (i.e. individuals in the different treatments were equally likely to migrate or become a resident).

The Gudsø Stream is located in east-central Jutland, Denmark, and flows through primarily agricultural areas before reaching the sea at Kolding Fjord (Fig. 1). The stream supports a natural population of brown trout as well as eel Anguilla anguilla and lam- prey Lampetra planeri. There is an old mill with a dam and millpond located $\sim 1 \mathrm{~km}$ upstream of the fjord. This landscape feature serves as a potential sink for outmigrating trout and is situated between our telemetry stations (see 'Biotracking' below). A fish ladder in this location provides both upstream and downstream access for migrating fish. Five regions of the Gudsø Stream upstream of the mill were sampled from March 6 to March 12, 2012 (Fig. 1). Transects 1 and 2 (0.4 and $1.1 \mathrm{~km}$ in length, respectively) were located on the main stem of the stream. Transects 3, 4, and 5 $(0.8,0.3$, and $0.5 \mathrm{~km}$ length, respectively) are sub-tributaries that flow into the main stem of the stream. All trout greater than $120 \mathrm{~mm}$ in total length were collected using a backpack electroshocking unit (Scubla ELT 60 II GI; run at 300 volts) and kept in a $60 \mathrm{l}$ container with fresh water.

\section{PIT tag insertion and cortisol treatment}

Trout were placed in a solution of $0.03 \mathrm{~g} \mathrm{l}^{-1}$ benzocaine until their opercular rate became slow and they did not respond to external stimuli ( 3 to $4 \mathrm{~min}$ ). This ensured that they were immobilized during the procedure. They were first measured (total length (TL) to nearest $1 \mathrm{~mm}$ ) and weighed (wet body mass to nearest $0.1 \mathrm{~g})$. Next, a small incision $(\sim 5 \mathrm{~mm})$ was made on the ventral-left side of the body anterior to the pelvic fin. A $23 \mathrm{~mm}$ PIT tag (Texas Instruments, RI-TRP-RRHP, $134 \mathrm{kHz}, 0.6 \mathrm{~g}$ mass in air) was inserted into the body cavity through the incision and the individual tag number was recorded. The tagging incisions were left to heal without suture closure. This approach was based on the standardized methods used for PIT tagging at the Technical University of Denmark and was performed in accordance with guidelines from the Danish Animal Experiments Inspectorate (License Number: 201315-2934-00808).

Immediately following PIT tagging, each trout was assigned into 1 of 4 treatment categories: control (CO), sham (SH), low-dose cortisol (LW), and highdose cortisol (HI). Treatments were assigned in a stratified random design, such that an attempt was made to ensure that the average size of fish in each category was equal. Following PIT tagging, $\mathrm{CO}$ fish were allowed to recover in a 601 container with fresh 
water until they were released (typically between 30 and $60 \mathrm{~min}$ ). Fish in the remaining 3 treatments received either an injection of plain cocoa butter $(\mathrm{SH})$ or a mixture of cocoa butter and cortisol prior to recovery (between 30 and $60 \mathrm{~min}$ ). To make the LW and HI cortisol treatments, $0.25 \mathrm{~g}$ and $1.00 \mathrm{~g}$ of cortisol were added to $100 \mathrm{ml}$ of melted cocoa butter, respectively. The cocoa butter treatments were reheated $\left(\sim 40^{\circ} \mathrm{C}\right)$ in the field to melt them and were shaken repeatedly throughout the administration process to prevent the cortisol from precipitating out of solution. Injections were made on the right ventral side of the body anterior to the pelvic girdle using an 18-gauge needle. The amount of cocoa butter or cortisol-cocoa butter given to each fish was dependent on the mass of the fish in a ratio of $0.01 \mathrm{ml}$ of cocoa butter to $1.0 \mathrm{~g}$ of fish. This resulted in cortisol dosages of $25 \mathrm{mg} \mathrm{kg}^{-1}$ for the LW treatment and $100 \mathrm{mg} \mathrm{kg}^{-1}$ for the high treatment.

While the magnitude of the plasma cortisol response is known to vary among individuals in laboratory studies (Fevolden et al. 1991, Pottinger et al. 1992), average baseline values for brown trout have been determined to range from 2 to $5 \mathrm{ng} \mathrm{ml}^{-1}$ rising up to $100 \mathrm{ng} \mathrm{ml}^{-1}$ following an acute stressor. In contrast to this drastic short-term increase, chronic stressors may result in long-term increases of 10 to $20 \mathrm{ng}$ $\mathrm{ml}^{-1}$ (Pickering et al. 1982). Pickering (1989) found that when using cocoa butter as a carrier, a dosage of $30 \mathrm{mg}$ of cortisol per $\mathrm{kg}$ of body mass raised circulating plasma levels to $15 \mathrm{ng} \mathrm{ml}^{-1}$ or within the range of a chronic stressor. Our LW treatment is therefore designed to simulate a chronic stressor that should last for 2 to 4 wk (Pickering \& Pottinger 1985). In keeping with previous studies that have found dosages of $50 \mathrm{mg} \mathrm{kg}^{-1}$ elevating cortisol levels for up to 5 wk (Pickering \& Duston 1983), the HI treatment ( $4 \times$ the LW concentration) is designed to elicit a more extreme response.

\section{Biotracking}

Two antenna arrays, each consisting of a pair of in-stream antennas spaced $\sim 5 \mathrm{~m}$ apart, were established near the bottom of the stream system (Fig. 1). The first station (S1) was located in the stream upstream of the millpond. The second station (S2) was located below the small fish ladder that connects the millpond to the downstream portion of the stream that flows to the ocean. This setup allowed us to determine when a fish entered the millpond (passed through S1) and when it exited in the seaward direc- tion (passed through S2). The distance between the 2 stations is $\sim 150 \mathrm{~m}$. It was not feasible to track trout beyond this point because the lower reaches of the stream pass through an extensive marshland for $\sim 1 \mathrm{~km}$.

To determine the efficiency of our antennas, we calculated in situ efficiency, which has 2 assumptions: (1) the probability of being detected at the first array is independent of the probability of detection at the second array, and (2) tagged fish passing through the first array are moving in the direction of the second array. These assumptions were met by our array design such that the distance between the 2 arrays is adequate to make detection probabilities independent, and trout entering the millpond are likely migrating to the ocean and therefore moving in the direction of S2. Based on these assumptions, in situ detection efficiency was calculated as the proportion of fish passing $\mathrm{S} 2$ that were also detected at S1.

\section{Growth measurements}

Approximately $110 \mathrm{~d}$ after tagging, on June 25 and 26, 2012, the 5 transects in the Gudsø Stream were resampled using a backpack electrofisher (Fig. 1). Trout that were captured were anaesthetized and tagged fish were identified using a PIT tag scanner (Agrident, APR350) then measured as described above. Trout were allowed to recover in a container (40 l) with aerated stream water for $15 \mathrm{~min}$ and then released into the stream. The instantaneous growth rate $(G)$ for both length and mass were calculated for all recaptured fish (Eq. 1; described in Schreck \& Moyle 1990).

$$
G=\left(\log _{\mathrm{e}} Y_{2}-\log _{\mathrm{e}} Y_{1}\right) /\left(t_{2}-t_{1}\right)
$$

Where $Y_{1}$ is the mass or length at the time of tagging $\left(t_{1}\right)$ and $Y_{2}$ is their mass or length at the time of recapture $\left(t_{2}\right)$. Both $t_{1}$ and $t_{2}$ are measured in days.

\section{Statistical analysis}

The total numbers of out-migrating fish detected at S1 and S2 were used as a proxy of migration survival. A chi-squared analysis was used to compare migration rates among treatments, with binary values for station passage (1) or no passage (0). It was assumed that trout that were detected at S2 also passed through S1.

ANOVA was used to compare the timing of migration (day of S1 and S2 passage), the time it took fish 
to reach S1 and S2 (days since tagging), and the initial mass, length and Fulton's condition factor $(K)$ of fish in each treatment, where $K=[$ mass $(\mathrm{g}) \times$ 100]/[length $\left.(\mathrm{cm})^{3}\right]$; Ricker 1975). Similarly, for fish recaptured in the stream, ANOVA was used to compare treatment effect on the instantaneous growth rate for both length $\left(G_{\mathrm{L}}\right)$ and mass $\left(G_{\mathrm{W}}\right)$. A post-hoc Tukey-Kramer analysis was conducted if ANOVAs were significant. Length and mass data were log transformed to equalize variance among treatments, except when used to calculate the instantaneous growth rate. A Fisher's exact test was used to compare both the number of instream recaptures relative to the total number of fish per treatment that did not pass a station and survival to $\mathrm{S} 1$ and $\mathrm{S} 2$ relative to the total number of treated fish between treatments. The variation reported with all values is given as standard deviation $( \pm \mathrm{SD})$. All analyses were performed in JMP v. 9.0.2 (SAS Institute).

\section{RESULTS}

\section{Tagging}

In total, 771 trout were PIT tagged and treated in roughly equal numbers (Table 1 ). There were no significant differences among treatment groups in terms of initial mass (ANOVA, $F=0.056, \mathrm{df}=3, \mathrm{p}=0.982$ ), length (ANOVA, $F=0.036, \mathrm{df}=3, \mathrm{p}=0.991$ ), or Fulton's condition factor (ANOVA, $F=1.645, \mathrm{df}=3, \mathrm{p}=$ 0.178 ; Table 1).

\section{In-stream recaptures}

A total of 96 trout were recaptured during the second sampling of the system that occurred on June 25 and 26. Roughly equal numbers of trout

Table 1. Salmo trutta. Mean initial length, mass, and condition (Fulton's condition factor) for trout in the 4 different treatments. Based on an ANOVA, there were no significant differences among treatments for these parameters. Variation is given as SD

\begin{tabular}{|lcccc|}
\hline Treatment & No. & $\begin{array}{c}\text { Length } \\
(\mathrm{cm})\end{array}$ & $\begin{array}{c}\text { Mass } \\
(\mathrm{g})\end{array}$ & $\begin{array}{c}\text { Condition } \\
\text { factor }(K)\end{array}$ \\
\hline Control & 194 & $14.8 \pm 2.4$ & $30.6 \pm 15.2$ & $0.918 \pm 0.059$ \\
Sham & 195 & $14.6 \pm 1.8$ & $30.2 \pm 12.2$ & $0.925 \pm 0.062$ \\
Low & 192 & $14.6 \pm 1.8$ & $30.6 \pm 13.1$ & $0.933 \pm 0.070$ \\
High & 190 & $14.7 \pm 2.0$ & $30.7 \pm 14.6$ & $0.922 \pm 0.074$ \\
\hline
\end{tabular}

Table 2. Salmo trutta. Recapture data from June 2012 for recapture length, mass, and condition factor (Fulton's condition factor $K$ ). Variation is given as SD. There were no significant differences among treatments

\begin{tabular}{|lcccc|}
\hline Treatment & $\begin{array}{c}\text { No. } \\
\text { recaptured }\end{array}$ & $\begin{array}{c}\text { Length } \\
(\mathrm{cm})\end{array}$ & $\begin{array}{c}\text { Mass } \\
(\mathrm{g})\end{array}$ & $\begin{array}{c}\text { Condition } \\
\text { factor }(K)\end{array}$ \\
\hline Control & 20 & $17.4 \pm 2.2$ & $56.5 \pm 24.8$ & $1.02 \pm 0.06$ \\
Sham & 22 & $17.2 \pm 1.8$ & $55.8 \pm 18.0$ & $1.07 \pm 0.08$ \\
Low & 28 & $16.8 \pm 2.2$ & $53.9 \pm 24.2$ & $1.08 \pm 0.07$ \\
High & 26 & $16.0 \pm 1.9$ & $45.7 \pm 19.7$ & $1.06 \pm 0.09$ \\
\hline
\end{tabular}

from the different treatment groups were recaptured (Table 2), with no significant difference in total number (Fisher's exact test, $\mathrm{p}>0.300$ for all combinations). In terms of instantaneous growth rate for mass, there was no significant difference between the $\mathrm{CO}$ and $\mathrm{SH}$ treatments $(0.65 \pm 0.19 \mathrm{~g}$ $\mathrm{d}^{-1}$ and $0.50 \pm 0.20 \mathrm{~g} \mathrm{~d}^{-1}$, respectively; ANOVA, $\mathrm{p}=$ 0.056; Fig. 2A). However, the LW and HI treatments had a significantly lower $G_{\mathrm{W}}$ than the $\mathrm{CO}$ treatment $\left(0.48 \pm 0.18 \mathrm{~g} \mathrm{~d}^{-1}\right.$ and $0.41 \pm 0.22 \mathrm{~g} \mathrm{~d}^{-1}$, respectively; ANOVA, $\mathrm{p}<0.001$; Fig. 2A). For lengthspecific growth, all treated fish had significantly lower $G_{\mathrm{L}}$ than CO fish (ANOVA, $\mathrm{p}<0.001$; Fig. 2B). While not significant, there was a decreasing trend in $G$ for both length and mass with the presence of cocoa butter and an increasing concentration of cortisol (Fig. 2). The length, mass, and condition factor did not differ among treatments (ANOVA, all $\mathrm{p}>0.100$; Table 2).

\section{Migration timing}

In total, 445 and 381 trout were detected passing S1 and S2, respectively. Of the 381 trout that passed S2, 14 had not been previously detected at $\mathrm{S} 1$. This allowed us to estimate the detection efficiency of $\mathrm{S} 1$ as $96.3 \%$. We were not able to calculate detection efficiency to S2. Trout were detected moving downstream from March 8 until June 8 (Days 68 and 160, respectively). There was a clear 'peak' in downstream migration that occurred from April 10 to April 13. The majority of tagged trout that passed through each station during the entire migration period were detected during that $4 \mathrm{~d}$ period $(56.7 \%$ at $\mathrm{S} 1$ and $68.8 \%$ at $\mathrm{S} 2)$. Neither the average day of passage at S1 and S2 nor the time (in days) to reach S1 or S2 was significantly different among treatment groups (ANOVA, all $\mathrm{p}>$ 0.100 ; Table 3). 

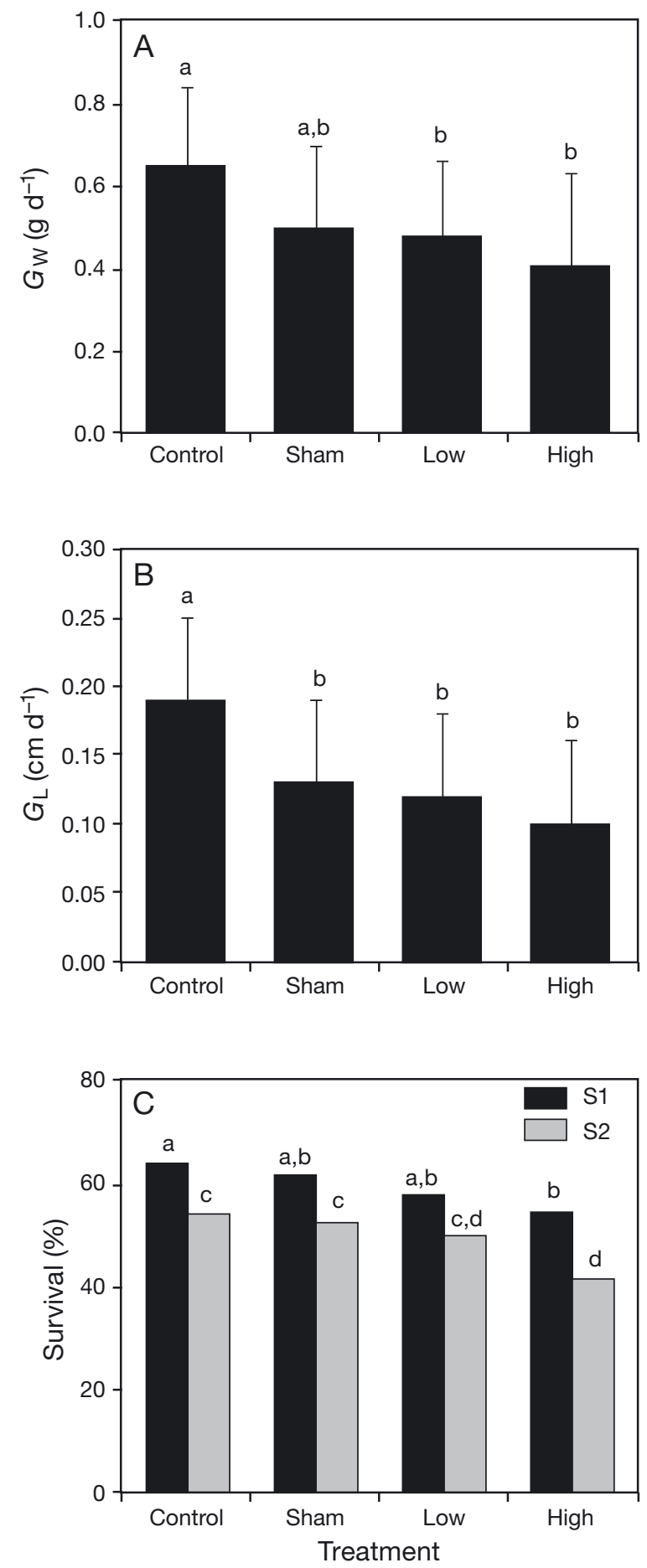

Fig. 2. Salmo trutta. Response of brown trout to 4 treatments: control (only PIT tagged), sham (PIT tagged and injected with cocoa butter), low-dose cortisol (PIT tagged and treated with a $25 \mathrm{mg} \mathrm{kg}^{-1}$ solution of cortisol) and high-dose cortisol (PIT tagged and treated with a $100 \mathrm{mg} \mathrm{kg}^{-1}$ solution of cortisol). Instantaneous growth rate for (A) mass $\left(G_{\mathrm{W}} ; \mathrm{g} \mathrm{d}^{-1}\right)$ and (B) length $\left(G_{\mathrm{Li}} \mathrm{cm} \mathrm{d}^{-1}\right)$. (C) Migration survival (\%) to PIT stations ( $\mathrm{S} 1$ and $\mathrm{S} 2$ ) for the 4 treatments. Values are means $\pm \mathrm{SD}$; different letters show significant differences at $\mathrm{p}<0.05$

\section{Survival to stations}

Trout in the HI treatment had significantly lower migration survival to S1 and S2 than trout in the CO treatments (Fisher's exact test; $\mathrm{p}=0.0303$ and $\mathrm{p}=$ 0.0189, respectively; Table 3, Fig. 2C). Survival to S2 for $\mathrm{HI}$ treated fish was also significantly lower than $\mathrm{SH}$ trout (Fisher's exact test; $\mathrm{p}=0.042$ ). There were no significant differences in survival between the other treatments (Fisher's exact test; $p>0.100$ ). Although not significant, there was a general trend towards lower survival with treatment and increasing cortisol concentration (Table 3, Fig. 2C).

\section{DISCUSSION}

Small-scale environmental changes can cause long-term or chronic levels of stress in fishes (Pickering \& Stewart 1984). Therefore, modifications to the natural environment are a potential source of stress for juvenile trout in their natal habitat. Furthermore, the impact of these stressors on a trout's physiological state during its transition to the ocean has important implications for the long-term viability of a population and is critical for maintaining a productive fishery. Using a combination of PIT telemetry and cortisol manipulation, we undertook one of the first experiments to test whether chronic stressors have carryover effects on individual survival, out-migration behaviour, and growth of wild, free-swimming sea trout smolts. Broadly, there was a consistent decreasing trend for growth and survival based on the degree of the stress that was applied.

\section{Growth}

Carryover effects are known to occur in wild populations of brown trout where, despite a starved individual's ability to make up for a weight deficit, their survival is still depressed over the long-term (Johnsson \& Bohlin 2006). Similarly, the long-term fitness of a fish can be depressed by cortisol manipulation (Gamperl et al. 1994, Schreck 2010). In this study, we observed a decrease in length- and mass-specific growth rate for recaptured trout that were part of the cortisol treatment groups (HI or LW) in comparison to the CO, but not compared to SH trout. Pre-smolt condition and growth in their natal freshwater streams is a critical period for ensuring a trout's long-term survival in the ocean, since larger fish entering the ocean often have higher survival rates (Rasmussen 
Table 3. Salmo trutta. Timing of detection at PIT stations (S1 and S2) and the percentage of trout from each treatment that passed each station. Different superscript letters for the proportion of fish reaching S1 and S2 as well as the number moving between S1 and S2 denote significant differences between treatment groups based on a Fisher's exact test (p < 0.05). No letters signifies no differences among treatments. Variation is given as SD

\begin{tabular}{|c|c|c|c|c|c|c|c|c|}
\hline Treatment & $\begin{array}{c}\text { Initial } \\
\text { no. }\end{array}$ & $\begin{array}{c}\% \\
\text { reaching } \\
\text { S1 }\end{array}$ & $\begin{array}{c}\text { No. of days } \\
\text { to } \mathrm{S} 1\end{array}$ & $\begin{array}{c}\text { Day } \\
\text { of } \\
\text { S1 passage }\end{array}$ & $\begin{array}{c}\% \\
\text { reaching } \\
\text { S2 }\end{array}$ & $\begin{array}{c}\text { No. of days } \\
\text { from } \\
\text { S1 to S2 }\end{array}$ & $\begin{array}{c}\text { Day } \\
\text { of } \\
\text { S2 passage }\end{array}$ & $\begin{array}{l}\text { \% moving } \\
\text { from } \\
\text { S1 to S2 }\end{array}$ \\
\hline Control & 194 & $64.1^{\mathrm{a}}$ & $33.0 \pm 10.8$ & $101.4 \pm 10.9$ & $53.9^{\mathrm{a}}$ & $3.8 \pm 5.7$ & $104.8 \pm 11.7$ & 84.0 \\
\hline Sham & 195 & $61.9^{\mathrm{ab}}$ & $34.9 \pm 9.6$ & $103.2 \pm 9.5$ & $52.3^{\mathrm{a}}$ & $3.4 \pm 5.6$ & $105.1 \pm 9.0$ & 84.2 \\
\hline Low & 192 & $57.8^{\mathrm{ab}}$ & $36.0 \pm 12.6$ & $104.1 \pm 12.3$ & $50.0^{\mathrm{ab}}$ & $2.7 \pm 5.7$ & $106.1 \pm 11.2$ & 86.5 \\
\hline High & 190 & $54.2^{\mathrm{b}}$ & $32.6 \pm 11.2$ & $100.9 \pm 11.1$ & $41.6^{\mathrm{b}}$ & $4.7 \pm 7.2$ & $103.0 \pm 11.5$ & 76.7 \\
\hline All Trout & 771 & 60.0 & $34.1 \pm 11.1$ & $102.4 \pm 11.0$ & 49.4 & $3.6 \pm 6.0$ & $104.8 \pm 10.9$ & 83.0 \\
\hline
\end{tabular}

1986, Bohlin et a. 1993, Jonsson et al. 1991). Therefore, the observed lower growth rates in treated fish ( $\mathrm{SH}, \mathrm{LW}$ and $\mathrm{HI}$ ) are evidence of a carryover effect from the early spring treatment, suggesting that stressors in their natal habitat can potentially decrease their long-term fitness.

Johnsson \& Bohlin (2006) documented compensatory growth in brown trout following a period of starvation. While we were unable to determine if such growth occurred in this study, given sufficient time it is possible that treated fish that experienced an allostatic load would eventually be able to recover such that their length and mass were similar to that of the control group. In Johnsson \& Bohlin (2006), it took 1 mo for trout to compensate for impaired body condition, whereas for length, it took some individuals up to $5 \mathrm{mo}$. In the current study, resident trout were recaptured within $\sim 3 \mathrm{mo}$, sufficient time for compensatory growth to improve their body condition. Unfortunately, we were not able to assess the instantaneous growth rates for trout that migrated from the system, although it is possible that growth would be even further depressed since migratory individuals tend to have higher metabolic rates than resident fishes (Forseth et al. 1999, Cucherousset et al. 2005). Future studies should attempt to assess the condition and growth rates of out-migrating individuals by re-capturing them along their migration pathway.

\section{Migration timing}

Despite the risks associated with migrating to the ocean, it is still beneficial for trout to undertake this migration because of the long-term benefit of increased reproductive capacity (Jonsson 1985). In freshwater tributaries, trout that grow faster and smoltify more quickly tend to migrate prior to smaller trout (Rasmussen 1986, Bohlin et al. 1993). Therefore, based on our observed depression in growth following treatment, we expected to see differences in the timing of treated versus untreated trout. Instead, treatment did not impact migration timing (i.e. stressed fish did not leave earlier or later to compensate for lower growth rates). Smolt status (resident or migratory) is largely determined in the fall and dependent on a trout's condition at that time (Metcalfe 1998). Therefore, despite the observed changes in length and mass following an early spring stressor (as seen in the recaptured individuals), all migratory trout still proceeded to exit the system at the same time. Furthermore, since there were no significant differences in terms of the number of trout recaptured from each treatment, it does not appear that an early spring stressor influences their ultimate smolt status.

While physiological status may determine whether a fish remains in a system or migrates out of the system (Nielsen et al. 2004, 2006), there is evidence that the actual timing of migration is more linked to environmental factors including photoperiod, temperature and water discharge (Hoar 1988, Aarestrup et al. 2002, Jonsson \& Jonsson 2002). Synchronized migration (i.e. migrating en mass), which may occur during periods of high flow, helps to reduce predation by increasing turbidity in the water, decreasing the amount of time it takes to exit the system, and reducing the probability of predation for individuals within a larger group (Aarestrup et al. 2002). Therefore, while a springtime stressor may change the growth patterns of individual fish, they will still migrate at the same time as other, less stressed individuals. Consistent migration timing has important implications for sub-populations that experience greater stressors than other populations in their region. If all trout are migrating at approximately the same time, then trout that experience a stressor in 
their natal grounds will ultimately be less successful because they will undertake the migration in an inferior condition. While it has been shown that stressed individuals can compensate for early stressors and the resulting growth depression (Johnsson \& Bohlin 2006), if there is not sufficient time for juvenile trout to compensate for this stressor (as in this study with an early spring stressor), they will likely be less successful in the ocean.

\section{Survival}

Migratory species are naturally exposed to higher levels of predation than their more resident counterparts (Gross et al. 1988), a pattern documented for brown trout (Elliott 1993). Despite the energetic advantages of migrating to the ocean, mortality rates can be double for trout that reach the ocean $\left(0.25 \% \mathrm{~d}^{-1}\right.$ in the ocean, $0.12 \% \mathrm{~d}^{-1}$ for resident fish; Elliott 1993). In addition, along the migratory pathway, mortality rates may also be quite high with documented mortality values ranging from 20 to $34 \%$ within a few days of entering the estuary (Jepsen et al. 2006, Koed et al. 2006). In a natal stream, we observed significantly fewer HI fish passing both stations in comparison to $\mathrm{CO}$ fish. There was also a general trend towards fewer fish passing the arrays with increasing cortisol dosages. Because we observed no differences among treatments in the number of recaptures, the observed decrease in passage was likely the result of increased in-stream mortality during migration for the treatment groups. O'Connor et al. (2010) observed increased locomotor activity in cortisol-treated fish, and since increased activity is associated with an increased risk of predation (Jönsson et al. 1996), the observed decrease in survival of HI trout could be driven by increased activity. However, it should be noted that if increased activity by $\mathrm{HI}$ trout was the main driver in their reduced survival, we would also expect lower numbers of $\mathrm{HI}$ individuals among our recaptures, which was not observed. It is also possible that cortisol treatment affected immunocompetence (Carlson et al. 1993, Espelid et al. 1996) such that disease contributed to mortality; however, we did not evaluate posttreatment immune function or disease burden. It is therefore likely that compared to migratory CO trout, multiple compounding issues act to decrease survival of migratory $\mathrm{HI}$ trout including lower length- and massspecific growth rates, decreased survival in-stream (whether due to predation or disease), and ultimately decreased survival upon reaching the ocean.

\section{Techniques}

PIT telemetry was a critical component of this study as it allowed us to tag and individually identify hundreds of fish rapidly, inexpensively, and with assumed minimal negative side effects (Ombredane et al. 1998, Gries \& Letcher 2002, Zydlewski et al. 2006). This technology is ideally suited for application in stream systems where fish cannot avoid the antenna array. The paired use of antenna allowed us to determine the direction of fish movement and resulted in high levels of detection efficiency (>95\%) relative to previous studies (Zydlewski et al. 2006). The most important advantage of this technology is that the tags will continue to function indefinitely allowing us to monitor the return migration of trout back into the Gudsø Stream. Although we did not conduct a tag retention study, previous tag retention studies on juvenile salmonids reveal high (i.e. > 99\%) retention of PIT tags such that tag loss is unlikely to be contributing to observed patterns (Gries \& Letcher 2002).

While the pairing of PIT telemetry with cortisol manipulation enabled us to individually assess a trout's response to a stressor, there are some limitations regarding cortisol manipulations that should be acknowledged. When cortisol is released following a natural stressor, its concentration typically decreases following a peak at $\sim 24 \mathrm{~h}$ due to a negative feedback loop (reviewed in Mommsen et al. 1999). The artificial increase in cortisol used in this study overrides this feedback and prolongs the stress response beyond a natural timeline. While this is a cause for concern, intracoelomic injection has been widely used (see Gamperl et al. 1994) since currently there are few alternatives that allow for the release of treated fish back into their natural setting. As such, the results presented in this study likely represent the extreme spectrum of possible outcomes for chronically stressed fishes. In addition, we did not measure cortisol titers in fish following injection. However, there have been numerous other studies that involve use of cortisol injection in a cocoa butter carrier on Salmo trutta (Pickering et al. 1982, Pickering 1989, Fevolden et al. 1991, Pottinger et al. 1992) such that there are well-established relationships between dose and subsequent level and duration of cortisol elevation. A surprising finding of this study was the apparent impact of the cocoa butter itself. Despite its previous successful use as a vector for cortisol for brown trout, we still observed significant impairment (relative to the CO group) in lengthspecific growth. Furthermore, despite a decreasing trend with the degree of treatment, the SH group was 
not statistically different from the cortisol-treated groups for length- and mass-specific growth, survival to S1, and survival to S2 (only for LW treatment). This would suggest that for wild trout, the intracoelomic injection of cocoa butter might act in a similar manner as an artificial elevation of endogenous cortisol.

In conclusion, using a combination of biotelemetry and a physiological manipulation we were able to track fitness-related endpoints of sea trout and show that a pre-migration experimental stressor increased in-stream mortality and impaired body condition. The long life span of PIT tags will enable us to continue to track fitness at an individual level and determine whether effects from a pre-migration stressor carryover as they grow and develop in the ocean and eventually return to their natal habitat to spawn.

Acknowledgements. Funding for this project was made possible through a NSERC Discovery Grant awarded to S.J.C. as well as grants to the Technical University of Denmark from the Danish National Fishing License Funds, and the Swedish Council for Forestry and Agricultural Research. S.J.C. is further supported by the Canada Research Chairs Program. The authors thank Michael Holm, Hans-Jørn Christensen, Jørgen Skole Mikkelsen, and Morten Carøe for assistance in the field and Eduardo Martins for statistical advice.

\section{LITERATURE CITED}

- Aarestrup K, Nielsen C, Madsen SS (2000) Relationship between gill $\mathrm{Na}+, \mathrm{K}+$-ATPase activity and downstream movement in domesticated and first-generation offspring of wild anadromous brown trout (Salmo trutta). Can J Fish Aquat Sci 57:2086-2095

Aarestrup K, Nielsen C, Koed A (2002) Net ground speed of downstream migrating radio-tagged Atlantic salmon (Salmo salar L.) and brown trout (Salmo trutta L.) smolts in relation to environmental factors. Hydrobiologia 483: 95-102

Barton BA, Iwama GK (1991) Physiological changes in fish from stress in aquaculture with emphasis on the response and effects of corticosteroids. Annu Rev Fish Dis 1:3-26

Boel M (2012) Life history types and strategies: case studies on brown trout (Salmo trutta) and alewives (Alosa pseudoharengus), involving physiological differences and interspecific interactions. PhD Thesis, Technical University of Denmark, Aarhus

Bohlin T, Dellefors C, Faremo U (1993) Timing of sea-run brown trout (Salmo trutta) smolt migration: effects of climatic variation. Can J Fish Aquat Sci 50:1132-1136

Carlson RE, Anderson DP, Bodammer JE (1993) In vivo cortisol administration suppresses the in vitro primary immune response of winter flounder lymphocytes. Fish Shellfish Immunol 3:299-312

> Carragher JF, Sumpter J, Pottinger T, Pickering A (1989) The deleterious effects of cortisol implantation on reproductive function in two species of trout, Salmo trutta L. and Salmo gairdneri Richardson. Gen Comp Endocrinol $76: 310-321$
Cooke SJ, O'Connor CM (2010) Making conservation physiology relevant to policy makers and conservation practitioners. Conserv Lett 3:159-166

> Cooke SJ, Hinch SG, Wikelski M, Andrews RD, Kuchel LJ, Wolcott TG, Butler PJ (2004) Biotelemetry: a mechanistic approach to ecology. Trends Ecol Evol 19:334-343

> Cucherousset J, Ombredane D, Charles K, Marchand F, Baglinière JL (2005) A continuum of life history tactics in a brown trout (Salmo trutta) population. Can J Fish Aquat Sci 62:1600-1610

Elliott JM (1993) The pattern of natural mortality throughout the life cycle in contrasting populations of brown trout, Salmo trutta L. Fish Res 17:123-136

Espelid S, Løkken GB, Steiro K, Bøgwald J (1996) Effects of cortisol and stress on the immune system in Atlantic Salmon (Salmo salar L.). Fish Shellfish Immunol 6:95-110

Fevolden SE, Refstie T, Roed KH (1991) Selection for high and low cortisol stress response in Atlantic salmon (Salmo salar) and rainbow trout (Oncorhynchus mykiss). Aquaculture 95:53-65

Forseth T, Nesje TF, Jonsson B, Hårsaker K (1999) Juvenile migration in brown trout: a consequence of energetic state. J Anim Ecol 68:783-793

Fraser DF, Gilliam JF (1992) Nonlethal impacts of predator invasion: facultative suppression of growth and reproduction. Ecology 73:959-970

> Fullerton AH, Garvey JE, Wright RA, Stein RA (2000) Overwinter growth and survival of largemouth bass: interactions among size, food, origin, and winter severity. Trans Am Fish Soc 129:1-12

Gamperl A, Vijayan M, Boutilier R (1994) Experimental control of stress hormone levels in fishes: techniques and applications. Rev Fish Biol Fish 4:215-255

Gibbons JW, Andrews KM (2004) PIT tagging: simple technology at its best. Bioscience 54:447-454

Gregory TR, Wood CM (1999) The effects of chronic plasma cortisol elevation on the feeding behaviour, growth, competitive ability, and swimming performance of juvenile rainbow trout. Physiol Biochem Zool 72:286-295

> Gries G, Letcher BH (2002) Tag retention and survival of age-0 Atlantic salmon following surgical implantation with passive integrated transponder tags. N Am J Fish Manag 22:219-222

Gross MR, Coleman RM, McDowall RM (1988) Aquatic productivity and the evolution of diadromous fish migration. Science 239:1291-1293

Harrison XA, Blount JD, Inger R, Norris DR, Bearhop S (2011) Carry over effects as drivers of fitness differences in animals. J Anim Ecol 80:4-18

Hoar WS (1988) The physiology of smolting salmonids. In: Hoar WS, Randall DJ (eds) Fish physiology, Vol 11. Academic Press, New York, NY, p 275-343

$>$ Hoogenboom MO, Armstrong JD, Miles MS, Burton $\mathrm{T}$, Groothuis TGG, Metcalfe NB (2011) Implantation of cocoa butter reduces egg and hatchling size in Salmo trutta. J Fish Biol 79:587-596

Iwama GK (1998) Stress in fish. Ann NY Acad Sci 851: 304-310

Jepsen N, Holthe E, Okland F (2006) Observations of predation on salmon and trout smolts in a river mouth. Fish Manag Ecol 13:341-343

Johnsson JI, Bohlin T (2006) The cost of catching up: increased winter mortality following structural growth compensation in the wild. Proc R Soc Lond B Biol Sci 273: 1281-1286 
Jonsson B (1985) Life history patterns of freshwater resident and sea-run migrant brown trout in Norway. Trans Am Fish Soc 114:182-194

> Jonsson B, Jonsson N (1993) Partial migration: niche shift versus sexual maturation in fishes. Rev Fish Biol Fish 3: 348-365

$>$ Jonsson N, Jonsson B (2002) Migration of anadromous brown trout Salmo trutta in a Norwegian river. Freshw Biol 47:1391-1401

Jonsson B, Jonsson N (2011) Ecology of Atlantic salmon and brown trout: habitat as a template for life histories. Fish and fisheries series 33. Springer, London

> Jonsson B, Jan Henning L, Heggberget TG, Jensen AJ, Johnsen BO, Næsje TF, Sættem LM (1991) Longevity, body size, and growth in anadromous brown trout (Salmo trutta). Can J Fish Aquat Sci 48:1838-1845

> Jönsson E, Johnsson JI, Björnsson BOT (1996) Growth hormone increases predation exposure of rainbow trout. Proc R Soc Lond B Biol Sci 263:647-651

Koed A, Baktoft H, Bak BD (2006) Causes of mortality of Atlantic salmon (Salmo salar) and brown trout (Salmo trutta) smolts in a restored river and its estuary. River Res Appl 22:69-78

Metcalfe NB (1998) The interaction between behavior and physiology in determining life history patterns in Atlantic salmon (Salmo salar). Can J Fish Aquat Sci 55: 93-103

> Metcalfe NB, Monaghan P (2003) Growth versus lifespan: perspectives from evolutionary ecology. Exp Gerontol 38:935-940

Mommsen TP, Vijayan MM, Moon TW (1999) Cortisol in teleosts: dynamics, mechanisms of action, and metabolic regulation. Rev Fish Biol Fish 9:211-268

- Nagrodski A, Murchie KJ, Stamplecoskie KM, Suski CD, Cooke SJ (2013) Effects of an experimental short-term cortisol challenge on the behaviour of wild creek chub (Semotilus atromaculatus) in mesocosm and stream environments. J Fish Biol 82:1138-1158

Nielsen C, Aarestrup K, Nørum U, Madsen SS (2004) Future migratory behaviour predicted from premigratory levels of gill $\mathrm{Na}+\mathrm{K}+$-ATPase activity in individual wild brown trout (Salmo trutta). J Exp Biol 207:527-533

> Nielsen C, Aarestrup K, Madsen SS (2006) Comparison of physiological smolt status in descending and nondescending wild brown trout (Salmo trutta) in a Danish stream. Ecol Freshw Fish 15:229-236

> Norris DR (2005) Carry-over effects and habitat quality in migratory populations. Oikos 109:178-186

O'Connor CM, Gilmour KM, Arlinghaus R, Hasler CT, Philipp DP, Cooke SJ (2010) Seasonal carryover effects following the administration of cortisol to a wild teleost fish. Physiol Biochem Zool 83:950-957

> O'Connor CM, Gilmour KM, Arlinghaus R, Matsumura S and others (2011) The consequences of short-term cortisol elevation on individual physiology and growth rate in wild largemouth bass (Micropterus salmoides). Can J Fish Aquat Sci 68:693-705

Økland F, Jonsson B, Jensen AJ, Hansen LP (1993) Is there a

Submitted: February 3, 2013; Accepted: August 18, 2013 threshold size regulating seaward migration of brown trout and Atlantic salmon? J Fish Biol 42:541-550

- Ombredane D, Bagliniere JL, Marchand F (1998) The effects of passive integrated transponder tags on survival and growth of juvenile brown trout (Salmo trutta L.) and their use for studying movement in a small river. Hydrobiologia 371/372:99-106

Pickering AD (1989) Environmental stress and the survival of brown trout, Salmo trutta. Freshw Biol 21:47-55

Pickering AD (1993) Growth and stress in fish production. Aquaculture 111:51-63

> Pickering AD, Duston J (1983) Administration of cortisol to brown trout, Salmo trutta L., and its effects on the susceptibility to Saprolegnia infection and furunculosis. J Fish Biol 23:163-175

Pickering AD, Pottinger TG (1985) Factors influencing blood cortisol levels of brown trout under intensive culture conditions. In: Lofts B, Holmes WN (eds) Current trends in comparative endocrinology. Hong Kong University Press, Hong Kong, p 1239-1242

Pickering AD, Stewart A (1984) Acclimation of the interrenal tissue of the brown trout, Salmo trutta L., to chronic crowding stress. J Fish Biol 24:731-740

Pickering AD, Pottinger TG, Christie P (1982) Recovery of the brown trout, Salmo trutta L., from acute handling stress: a time-course study. J Fish Biol 20:229-244

> Pottinger TG, Pickering AD, Hurley MA (1992) Consistency in the stress response of individuals of two strains of rainbow trout, Oncorhynchus mykiss. Aquaculture 103: 275-289

Rasmussen G (1986) The population dynamics of brown trout (Salmo trutta L.) in relation to year-class size. Pol Arch Hydrobiol 33:489-508

Redding JM, DeLuze A, Leloup-Hatey J, Leloup J (1986) Suppression of plasma thyroid hormone concentrations by cortisol in the European eel Anguilla anguilla. Comp Biochem Physiol A 83:409-413

Ricker WE (1975) Computation and interpretation of biological statistics of fish populations. Bull Fish Res Board Can 191

Schlosser IJ (1991) Stream fish ecology: a landscape perspective. Bioscience 41:704-712

Schreck CB (2010) Stress and fish reproduction: the roles of allostasis and hormesis. Gen Comp Endocrinol 165: 549-556

Schreck CB, Moyle PB (1990) Methods for fish biology. American Fisheries Society, Bethesda, MD

- Wang L, Lyons J, Kanehi P, Bannerman R, Emmons E (2000) Watershed urbanization and changes in fish communities in southeastern Wisconsin streams. J Am Water Resour Assoc 36:1173-1189

> Zydlewski GB, Haro A, Whalen KG, McCormick SD (2001) Performance of stationary and portable passive transponder detection systems for monitoring of fish movements. J Fish Biol 58:1471-1475

> Zydlewski GB, Horton G, Dubreuil T, Letcher B, Casey S, Zydlewski J (2006) Remote monitoring of fish in small streams. Fisheries 31:492-502

Proofs received from author(s): November 7, 2013 